\title{
Evaluating cost taxonomies for information systems management
}

\author{
Zahir Irani $^{\mathrm{a}, *}$, Ahmad Ghoneim ${ }^{\mathrm{a}}$, Peter E.D. Love ${ }^{\mathrm{b}}$ \\ a Information Systems Evaluation and Integration Network Group (ISEing), Department of Information Systems and Computing, \\ Brunel University, Uxbridge UB8 3PH, UK \\ ${ }^{\mathrm{b}}$ We-B Centre, School of Management Information Systems, Faculty of Business and Public Management, \\ Edith Cowan University, Joondalup, WA 6027, Australia
}

Available online 19 August 2005

\begin{abstract}
The consideration of costs, benefits and risks underpin many Information System (IS) evaluation decisions. Yet, vendors and project-champions alike tend to identify and focus much of their effort on the benefits achievable from the adoption of new technology, as it is often not in the interest of key stakeholders to spend too much time considering the wider cost and risk implications of enterprise-wide technology adoptions. In identifying a void in the literature, the authors of the paper present a critical analysis of IS-cost taxonomies. In doing so, the authors establish that such cost taxonomies tend to be esoteric and difficult to operationalize, as they lack specifics in detail. Therefore, in developing a deeper understanding of IS-related costs, the authors position the need to identify, control and reduce IS-related costs within the information systems evaluation domain, through culminating and then synthesizing the literature into a frame of reference that supports the evaluation of information systems through a deeper understanding of IS-cost taxonomies. The paper then concludes by emphasizing that the total costs associated with IS-adoption can only be determined after having considered the multi-faceted dimensions of information system investments.
\end{abstract}

(C) 2005 Elsevier B.V. All rights reserved.

Keywords: Costs; Taxonomies; Evaluation; Indirect costs; Hidden costs

\footnotetext{
* Corresponding author. Tel.: +44 1895 816211; fax: +44 1895816242.

E-mail address: zahir.irani@brunel.ac.uk (Z. Irani).
}

\section{Introduction}

Organizations increasingly rely on Information Systems (IS) to acquire a competitive edge, with this often translating to an increased budget allocation to support their investments in an IS infrastructure. The purchase of Information 
Technology (IT) and development of an IS are seen as a source of increasing cost and concern to management $[7,17]$. In-line with the rapid advancements in IT, and with the cost of technology continuing to fall, it is no longer efficient for management to try and reduce direct infrastructure costs alone, as competitors are able to secure similar if not the same discount on hardware and software.

There is the widespread recognition of the need to consider the social and organizational implications associated with the adoption of IT/IS from a cost perspective, if management are to seek competitiveness through reducing their IS-costs. Adding to the complexity of socio-organizational cost identification and evaluation is then the difficulty of their accommodation within the portfolio of investment appraisal techniques available to management [12]. As IS increasingly evolve with the needs of the business environment through the use of improved integration technologies, any robust evaluation process will require a deeper understanding of the cost implications throughout the information systems projects' lifecycle [14]. In doing so, allowing managers to develop a better understanding of the implications associated with their investment as it matures and evolves. It is here where this paper attempts to address a void in the literature, through developing a frame of reference that will allow decision-makers to the navigation through the portfolio of cost taxonomies for information systems evaluation.

\section{Information system investments evaluation}

Information system investments differ in nature from other capital investments as there is a substantial human and organizational interface [12] along with characteristics such as high risk, long-term return with erratic timing of cash-flows, portfolio of benefits, significant proportion of intangible/hidden costs and substantial risk [18]. Despite these characteristics, IS projects are often evaluated using the same traditional appraisal techniques as those used for other more traditional capital investments, such as facilities purchase or manufacturing systems. Milis and Mercken [18] summarize in Fig. 1 the reasons for this management practice.

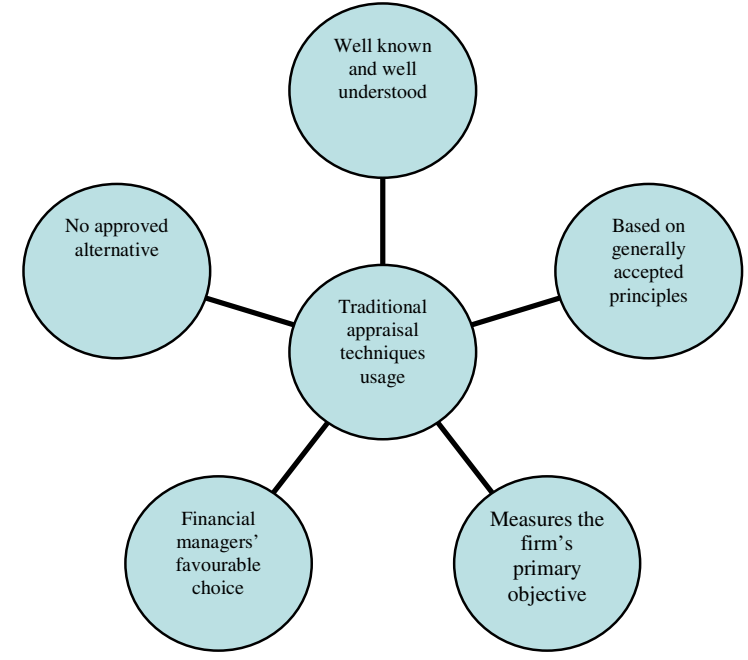

Fig. 1. Reasons for using traditional appraisal techniques.

Appraisal techniques are used by decision-makers to support their evaluation of an investments case. Irani and Love [12], identified some of the reasons why companies appraise IT/IS investments:

- comparison between different projects;

- rank projects in terms of organizational priorities;

- justify investment requests by management;

- control expenditure, benefits, risk, development and implementation of projects;

- provide a framework that facilitates organizational learning;

- mechanism to decide whether to fund, postpone or reject investment requests.

Although these reasons demonstrate the importance of an investment appraisal process and add weight to the use of such techniques, Primrose [22] points out that 'many managers view project appraisal as a financial hurdle that has to be overcome and not as a techniques for evaluating the project's worth'.

Information system projects are increasingly a multi-stakeholder investment that impacts the organization and increasingly its supply or service chain. According to Milis and Mercken [18], there are five parties involved in information technology 
Table 1

IT investment stakeholders

\begin{tabular}{ll}
\hline Parties involved in IT investments & Objectives and expectations \\
\hline Organization (Management) & $\begin{array}{l}\text { Interested in the gains [financial/and other] generated by the investment } \\
\text { Seeks to ensure that the project is implemented on time, within budget } \\
\text { and to user requirements } \\
\text { Technology should meet their requirements while integrating flexibility to adapt to the } \\
\text { changing requirements of users/customers }\end{array}$ \\
Users & $\begin{array}{l}\text { Focus on short-term criteria set by sponsors (used to judge their performance) } \\
\text { Froject team (Implementers) }\end{array}$ \\
$\begin{array}{l}\text { Fupporters (Sub-contractors) } \\
\text { Stakeholders (do not benefit from } \\
\text { or influence the investment) }\end{array}$ & $\begin{array}{l}\text { Consists of many groups, each with its own goals and objectives } \\
\text { Might support or oppose the investment - possible covert resistance }\end{array}$ \\
\hline
\end{tabular}

investments; each having their own set of objectives and expectations. If the evaluation of IT/IS investments are only financially based, and centre on the use of traditional appraisal techniques then, the process only serves the objective of management. This means neglecting all other parties' objectives and accordingly, failing to incorporate crucial factors that might affect the willingness of these parties to cooperate in realising the objectives of the investment. Table 1 summarizes the different parties (stakeholders) and their expectations from the IT/IS investment, and demonstrates that any form of evaluation must be multi-faceted and seek to have their inclusion whilst considering the agendas of the different stakeholders involved.

Choosing an evaluation approach that seeks to go beyond the traditional boundaries of financial evaluation is increasingly important, and many factors associated with developing a robust information system requires a business, user and technology context. Therefore, providing decisionmakers with direct cost analysis, cash-flow projections, financial figures, etc., will not be enough, as there are other strategic, softer, political and social factors that need to be considered during the evaluation process. Notwithstanding, it remains important to ensure that financial transparency exists, as companies can all afford to fund investments that provide little or no financial return.

\section{Information systems evaluation techniques}

Information system projects are often evaluated using traditional appraisal techniques $[2,3]$. Renk- ema and Berghout [25] have identified an exhaustive list of approaches to investment appraisal. This work has more recently been extended by Irani and Love [10], where the various approaches to investment appraisal have been classified. Irani and Love [12] presented a taxonomy that culminates a variety of appraisal methods available to decision-makers. They present traditional economic approaches, strategic approaches, and analytical approaches, along with emerging integrated techniques; developed to accommodate illusive indirect costs that are increasingly associated with IT/IS projects. Milis and Mercken [18] have also presented a variety of ex ante evaluation techniques used to justify capital investments in IT/IS. These techniques are presented in Table 2 .

A further perspective is a move away from generic appraisal techniques, and is one of matching information systems projects based on their

Table 2

Milis and Mercken's [18] ex ante evaluation techniques

\begin{tabular}{ll}
\hline Appraisal method & Techniques \\
\hline $\begin{array}{c}\text { Traditional evaluation } \\
\text { methods }\end{array}$ & Payback period \\
& Return on investment \\
& Internal rate of return \\
& Net present value
\end{tabular}

Adjusted traditional evaluation methods

Adjusted cost/benefit analysis Discount rate sensitivity Adjusted interpretation process

New evaluation techniques Strategic fit Information economics The options model

Mixed evaluation methods Multi-layer evaluation process Balanced scorecard 
characteristics to sympathetic techniques. A study by Hochstrasser [9] divided up IT projects based on their objective. The research classified information system projects into groups that share similar objectives:

- Infrastructure projects: Hardware or software systems installed to enable the subsequent development of front-end systems.

- Cost replacement projects: IT systems introduced to automate manual activities.

- Economy of scale projects: Systems introduced to allow a company to handle an increased volume of data.

- Economy of scope projects: IT systems introduced to allow a company to perform and extended range of tasks.

- Customer support projects: IT systems introduced to offer better services to customers.

- Quality support projects: IT introduced to increase the quality of the finished product.

- Information sharing and manipulation projects: IT systems introduced to offer better information sharing and information manipulation.

- New technology projects: IT systems introduced to exploit strategically the business potential of the new technology, to do things that were not possible before.

The view here could be to match a particular appraisal technique to one of the above project characteristics. For example, if the project were a cost replacement project, where the costs are direct in nature, and benefits largely efficiency gains then, such an investment can be evaluated using traditional economic appraisal approaches such as, ratio based or discounted approaches. However, if the investment is a new technology project with a substantial strategic dimension which would translate into intangible benefits and indirect costs, then approaches like the balanced score card might well be more appropriate.

Having said this however, the focus of this paper is not to look into the evaluation techniques per say but rather, to explore the much overlooked cost taxonomies that form an integral part of the decision-making process; inclusion with investment appraisal techniques.

\section{Cost taxonomies and factors}

The problem of IT/IS cost identification remains one routed in the experiences and knowledge inherent in individuals or project teams. According to Powell [21], there is a need for a mechanism to identify and allocate IS costs. Yet managers generally do not have the knowledge and experience to identify and manage such costs [13]. What makes the process of identification and allocation more complicated is that different kinds of costs occur within and outside the scope of the IS function [20]. Furthermore, it is the difficulty of identifying these often hidden costs together with not being able to adequately support their control and reduction that frustrates many project champions. In culminating the limited literature in the area of IT/IS cost evaluation, Table 3 presents a summary of cost taxonomies that will now be analyzed and the synthesized in this paper.

\section{Initial/ongoing cost taxonomy}

According to Dier and Mooney [5], IT costs can be classified as initial and ongoing costs. Together they compose the lifetime cost of a system. In this context, lifetime cost is defined as the "total attributable cost that is incurred throughout the life of an application' while the ongoing costs are defined as 'the costs incurred from year to year in maintaining and modifying the application [including integration]'. Dier and Mooney [5] suggest that costs within the two categories are often well known to IT managers, though their impact is not always fully understood, especially the identification, scale and magnitude of the ongoing costs. This is due in part, to the infrequent and unexpected occurrence of modification costs, for example those which occur when there is a need to change business practices or when new technology is introduced mid-project.

\subsection{Initial costs}

Initial costs occur during the system planning, testing, implementation phase, and, typically include the following costs: 
Table 3

Cost classification models

\begin{tabular}{|c|c|c|}
\hline Taxonomy & Description & Author \\
\hline Initial/ongoing costs & $\begin{array}{l}\text { These costs are identified and assigned during } \\
\text { the systems lifecycle. However, they tend to be } \\
\text { retrospective, which make their consideration } \\
\text { during ex ante evaluation difficult. Yet, as legacy } \\
\text { systems and enterprise solutions become more } \\
\text { integrated, such cost taxonomies warrant closer } \\
\text { consideration in terms of identifying their } \\
\text { respective cost elements }\end{array}$ & Dier and Mooney [5] \\
\hline Financial/non-financial activities & $\begin{array}{l}\text { These costs are classified according to the activities } \\
\text { causing them thus, emphasizing a causal relationship. } \\
\text { Hence, reactive in nature }\end{array}$ & Kusters et al. [16] \\
\hline Initial investment/ongoing costs & $\begin{array}{l}\text { These are based around the costs relating to the } \\
\text { development of an information system infrastructure } \\
\text { (initial investment) and operation of the } \\
\text { infrastructure (ongoing cost) }\end{array}$ & Remenyi et al. [23] \\
\hline Development/hidden costs & $\begin{array}{l}\text { Costs related to purchasing, installing, training, } \\
\text { and testing the system }\end{array}$ & Anandarajan and Wen [1] \\
\hline Social subsystem costs & $\begin{array}{l}\text { Those costs that reflect the changes in the social } \\
\text { subsystem brought about by a new IT }\end{array}$ & Ryan and Harrison [26] \\
\hline Direct/indirect costs & $\begin{array}{l}\text { The direct cost element is assigned to the information } \\
\text { technology component, whereas the indirect element } \\
\text { relates to the effect of the information systems on } \\
\text { the organization and the people }\end{array}$ & Irani et al. [13] \\
\hline $\begin{array}{l}\text { IS cost divisions: Management, employee, } \\
\text { finance, and maintenance }\end{array}$ & $\begin{array}{l}\text { This cost taxonomy identifies a set of cost factors } \\
\text { and sub-systems that impact the organization. } \\
\text { However, this taxonomy falls short of identifying } \\
\text { performance measure }\end{array}$ & Mohamed and Irani [19] \\
\hline $\begin{array}{l}\text { Acquisition/administration: Control } \\
\text { and operation costs }\end{array}$ & $\begin{array}{l}\text { The model identifies a set of cost factors that } \\
\text { constitute the total cost of ownership of information } \\
\text { technology }\end{array}$ & David et al. [4] \\
\hline
\end{tabular}

- Hardware: The costs of purchasing the necessary IT infrastructure components such as computers, printers, scanners, disks, etc.

- Communication: The costs of the communication devices such as network adaptors, database servers, network cards, and telephone lines/ leased lines rentals.

- Packages software: The costs of the ready-made/ on the shelf software such as office software or any other program needed for the system.

- Custom software: The costs of any bespoke software specifically designed to meet the needs of a system such as the development of a database.

- Cabling/building: The cost of building or readjusting the building facilities in terms of electri$\mathrm{cal} /$ communication/network wiring costs, as well as the costs of re-designing the building such as suspended ceilings for ventilation sys- tems and false floors to accommodate the electric and communication equipment.

- Data conversion: The costs of converting the old data types previously used into new data types accepted by the new system (e.g., converting the data of a COBOL database to be transferred into a newly acquired Oracle database).

- Project management: The cost associated with the time, effort, and material consumed by the project team when planning, designing, implementing, and managing the new system.

Increasingly, organizations allocate substantial resources to the management of the project both ex ante and ex post. With this in mind, project management expenses can be classified as ongoing costs and are increasingly identified within the business case. 


\subsection{Ongoing costs}

On going costs are the yearly costs incurred to maintain and modify the hardware and software of a system, thus ensuring that it [system] is aligned to its original objectives [case] and/or changed business direction. These costs include but are not limited to:

- Hardware maintenance: The costs of the regular maintenance and the accidental repairs needed for the hardware devices, such as the printers, computers, air conditioners, damaged communication/wires and electronic devices such as hard disks, screens, etc.

- Licenses: The per year costs of the licensing right for making more than one copy of a software for example when buying an original copy of Windows 2000, a company makes 200 extra copies for its employees paying a yearly license fee.

- Software maintenance: The cost of maintaining the software represented in the daily backup of the database to save current transactions on order to avoid loss of data in case of sudden system crashes.

- Support: The cost of internal/external support needed in case of problems, damages in either the software or the hardware. If an external party (the hardware/software vendor) does the support, in most cases he also does the maintenances.

- Ongoing training: The cost of training the staff onsite/offsite when updating software.

- Modifications: The costs of modifying a system according to the new business needs or vice versa.

- Upgrades: The costs of both hardware and software upgrades. Though, it should be noted that upgrading might sometimes be included in a software maintenance contract.

- System staff: The costs caused by increases in the systems staff salaries due to their skill enhancement and their gained experience in dealing with the new system.

- Consumables: The costs of items consumed during the system operation such as ink cartridges, toners, printing paper, disks, CD's, backup tapes, etc.
- Insurance: The cost of the yearly insurance of the buildings, the hardware, the software (against theft), as well as against fire, and any environmental crisis such as earthquakes, etc.

Dier and Mooney [5] and Wheatley [28] suggest that the initial costs of many IT projects represent a small percentage of its total lifetime cost. This suggests that a significant gap existed between the expected ongoing cost during ex ante evaluation and the actual ongoing cost during ex post evaluation. Table 4 presents a taxonomy for initial and ongoing costs.

\section{Financial/non-financial activity taxonomy}

Kusters and Renkema [16] classify the costs associated with IT/IS projects in accordance with the activities that induce them. They categorise activities as being either financial or non-financial (Tables 5 and 7). The financial activities presented in Table 5 are direct costs, and include for example development, implementation, operations, etc. [of a system]. Kusters and Renkema [16] identified those activities that directly induce cost and which can be easily identified and traced in monetary terms thus, included within traditional economic based appraisal techniques.

Table 6 presents a further analysis of each 'financial' activity when matched with its relevant cost factor.

In exploring this analysis further, the development activity of a new system for example, has a direct financial impact attributed to software development and the acquisition of hardware and other direct costs. Also consultancy might be a cost factor during the development of a new system. Phasing out is another activity during which the old system is replaced with a new system. This process is lengthy and may require doubled-activities and therefore double cost (maintenance), for both the old and the new systems during the transition phase. Therefore, cost factors such as staffing, software and hardware maintenance, and some consultancy might occur. Clearly, these activities or processes have a direct financial impact on the overall budget of a system and need 
Table 4

Initial and ongoing cost taxonomy (adapted from Dier and Mooney [5])

\begin{tabular}{ll}
\hline Cost categories & Description \\
\hline $\begin{array}{l}\text { Initial costs } \\
\text { Hardware }\end{array}$ & $\begin{array}{l}\text { Cost of purchasing equipments, e.g., computers, printers } \\
\text { Communication }\end{array}$ \\
$\begin{array}{l}\text { Cackage software } \\
\text { Custom software }\end{array}$ & $\begin{array}{l}\text { Costs of ready made software, e.g., office integrated software } \\
\text { Costs of in-house application development }\end{array}$ \\
$\begin{array}{l}\text { Systems software } \\
\text { Cabling/building }\end{array}$ & $\begin{array}{l}\text { Cost of the operating systems used, e.g., windows NT } \\
\text { Cost of building or readjusting buildings to accommodate network wiring, e.g., false floors }\end{array}$ \\
Project management & $\begin{array}{l}\text { Cost of converting old data format into new data format, e.g., upgrading } \\
\text { from an Cobol DB to an Oracle DB }\end{array}$ \\
Ongoing costs & Cost associated with time and effort dedicated by project team during the project's life cycle \\
Hardware maintenance & \\
Software maintenance & Cost of regular or irregular/emergency maintenance, e.g., printers malfunction \\
Licences & Cost of maintenance to make a computer program usable in a changed environment \\
Support & Allowing an individual or group to use a piece of software \\
Ongoing training & Cost of technical internal/external support needed, e.g., software/hardware vendor \\
Modifications & Cost of training the staff onsite/offsite when updating the systems used \\
Cost of modifying the system according to the new business needs or vice versa, \\
Upgrades
\end{tabular}

Table 5

Financial criteria (adapted from Kusters and Renkema [16])

Cost inducing activities Cost related factors

Development: Cost of development of a full or a part of a system

Training: Pre- and post-implementation training for the different users of the system

Implementation: This cost should include all the other activities involved in the project

Software

Hardware

Staffing

Operations: Any elements needed for the operation of the system, storage devices, paper, electricity Consultancy

Maintenance: Contract maintenance or on call maintenance costs

Security: Includes anti-virus software, firewalls, and physical security of the facilities

Travel

Printing

Phasing out: Cost of double maintenance and operation of both new and old systems during the phasing out stage

Table 6

Mapping the cost factors to the financial activities

\begin{tabular}{|c|c|c|c|c|c|c|}
\hline \multirow[t]{2}{*}{ Financial activities } & \multicolumn{6}{|c|}{ Cost related factors } \\
\hline & Software & Hardware & Staffing & Consultancy & Travel & Printing \\
\hline Development & $\checkmark$ & $\checkmark$ & $\checkmark$ & $\checkmark$ & & \\
\hline Training & $\checkmark$ & & $\checkmark$ & $\checkmark$ & $\checkmark$ & \\
\hline Implementation & $\checkmark$ & $\checkmark$ & & $\checkmark$ & & \\
\hline Operations & $\checkmark$ & $\checkmark$ & $\checkmark$ & & & $\checkmark$ \\
\hline Maintenance & $\checkmark$ & $\checkmark$ & & & $\checkmark$ & \\
\hline Security & $\checkmark$ & $\checkmark$ & & $\checkmark$ & & \\
\hline Phasing out & $\checkmark$ & $\checkmark$ & $\checkmark$ & $\checkmark$ & & \\
\hline
\end{tabular}


Table 7

Non-financial activities (adopted from Kusters and Renkema [16])

\begin{tabular}{ll}
\hline Non-cost inducing activities & Cost related factors \\
\hline Transformation & Re-designing the business process \\
Technology & Integration and standardization \\
Compliance to external necessities & Political pressure, legal necessity \\
Wider human and organizational impacts & Organizational structure, organizational learning, new work contents \\
Development risks & Development staff, application risks technological risk \\
Implementation risks & Resistance to change, lack of application knowledge, conversion \\
\hline
\end{tabular}

to be accommodated within any form of rigorous evaluation.

Table 7 presents the non-financial activities identified by Kusters and Renkema [16]. The non-financial activities can be described as a set of scenarios that might occur during the various stages of a systems' lifecycle. In other words, they are a set of activities that are related to the human and organizational aspects of developing, and implementing a new system.

The various activities shown in Table 7 can indirectly induce costs that are difficult to quantify or estimate; even possibly trace to the information system Also, the magnitude of these activities cannot be predicted as they depend on peoples' behaviour towards the system, politics, and a variety of internal and external risk factors. People are inherently different and interface differently even in the same circumstances. All of these factors have a non-financial effect but they indirectly induce costs. For example, resistance to change or lack of application knowledge could result in the system being not used effectively, or at all by some employees who do not want to change the way they work. This would result in a decrease in productivity. Similarly, gaining top managements support is considered a political imperative to secure the funding needed for a new system.

\section{Initial investment and ongoing cost taxonomy}

Remenyi et al. [23] identify and classify IT/IS costs in a more generic model than that proposed by Dier and Mooney [5]. In Table 8 the costs are categorized as initial and ongoing investment costs.
Table 8

Initial investment and ongoing costs [23]

\begin{tabular}{ll}
\hline Initial investment costs & Ongoing costs \\
\hline Hardware & Staff \\
Software & Maintenance \\
Data communications & Accommodation \\
Commissioning & General expenses \\
Infrastructure & \\
Staff related costs & \\
\hline
\end{tabular}

These cost classification criteria are used to calculate the return on investment (ROI) [23]. The $\mathrm{ROI}$ is an integral part of many capital budgeting processes, and is used to compare the financial cost of acquiring and implementing an IS with the tangible and measurable benefits that the organization derives from the use of the system. In addition, upgrading costs and consultancy costs can be added to the list of ongoing costs. Most of the cost elements identified by Remenyi et al. [23] can be grouped under one generic cost element, such as infrastructure, which can accommodate hardware and data communication costs. Training costs were not identified, although under a generic classification they could be considered as a subset of staff costs. However, commissioning cost is a vague element, which was identified by the authors as a staffing consultancy cost, sourced from outside parties during the planning, design and implementation of the systems' infrastructure. In summary, the classification proposed by Remenyi et al. [23] would appear to be a higher level classification of that proposed by Dier and Mooney [5]; which does not offer managers enough detailed information about the cost portfolio of IS investments thus, is likely to be of little support during the appraisal process. 


\section{Development and hidden cost taxonomy}

Anandarajan and Wen [1] proposed an approach to evaluate IT/IS using existing techniques that have been modified to incorporate both tangible and intangible benefits and costs. They stress that little attempt has been made to identify and then incorporate hidden costs. In their study, they developed a framework for identifying hidden costs in IT/IS projects by considering all the relevant stages in project implementation from the point of view of both technical personnel involved in development and end users. This framework is part of a three steps methodology for IT evaluation. The IT evaluation methodology attempts to identify the tangible and intangible costs and benefits, as well as net present values and risk assessment.

Drawing from the literature, Anandarajan and Wen [1] presented a framework that incorporates IT/IS investment costs identified by Earl [6] in 1989. Such costs are classified into: costs incurred by technical staff responsible for developing the system and costs incurred by the user in learning to use the technology. First, costs are analyzed based on those incurred at the development stage such as, initial feasibility study, conceptual design, physical design, developed prototypes, cost of hardware, software and assistant expenditure. Second, costs are analyzed based on those incurred at the operations level, which include preparation of data, initial cost of supplies.

The authors of this paper combined both models proposed by Anandarajan and Wen [1] and
Earl [6]. The resulting model is shown in Table 9, which shows the development and operations categories cross-classified with the technical staff and user categories.

Anandarajan and Wen [1] state that while the costs incurred by the technical staff are actual expenditures, the costs by users may not involve cash outlays and hence are more difficult to determine and thus, estimate. In other words, they are hidden and intangible in nature. For example, while users are trained to use the system, they are not being productive in the short-term, yet their salaries are paid irrespectively. While their model is considered one step towards understanding the full range of costs and benefit of IT/IS; as technology becomes more sophisticated, organizations may never fully achieve a total understanding of the range of IT/IS related costs.

\section{Social subsystem cost taxonomy}

Responding to what appears to be a lack of payoff in IT/IS investments, researchers as well as practitioners have suggested that traditional valuation analyses are incomplete and have called for additional work to identify hidden costs and benefits [26]. In an attempt to improve understanding of a major causes of these hidden costs and benefits, Ryan and Harrison [26] investigated the changes in the social subsystem brought about by new information technology.

During their study, Ryan and Harrison [26] interviewed 50 IT decision-makers in a variety of

Table 9

Development/hidden costs

\begin{tabular}{lll}
\hline Cost factors & Technical staff driven costs & User driven (hidden/intangible) costs \\
\hline Development & Hardware/software purchase & Development effort \\
& Hardware/software usage & Implementation and conversion \\
& Systems analysis and programming & Education and training time \\
& Professional education and training & Data development and collection \\
Application selling and marketing & Displacement and disruption \\
Operations & Communications & \\
& Hardware/software use & Support staff \\
& Data preparation & Data management \\
& Supplies and services & Data collection \\
& Maintenance & Maintenance \\
& Communications & User resistance \\
\hline
\end{tabular}


industries in an attempt to know what, when, and how often social subsystem considerations are included in IT investment decision-making. By incorporating social subsystem costs and benefits in the IT investment process, decision-makers were considered able to gain a greater appreciation for hidden costs and benefits and thus, able to anticipate IT payoff.

Social subsystems incorporate all that is human, and inclusive of what members of an organization bring with them to work. It is composed of employees and the knowledge, skills, interrelationship, attitudes, and the needs they bring to the work environment. Thus, Ryan and Harrison [26] consider the terms 'social subsystem' and 'human related' costs as synonymous. Social subsystem costs are those cost that originate from employees' expertise, judgements, decisions, and task interdependencies. A list of the social subsystem costs identified by Ryan and Harrison [23] is shown below:

- system development, implementation and integration;

- training and education of staff;

- communication within the project team and organization;

- hardware;

- package software;

- upgrades to later editions [operating system and software];

- employee time;

- infrastructure and technology fabric;

- learning curve before the users are able to fully exploit the system.

When decision-makers ignore these social subsystem costs during their investment evaluation, they assume that these social subsystem costs do not exist or are insignificant. In reality, these costs do occur and are significant but are often hidden to the decision-making process [6-9], possibly because traditional appraisal approaches are unable to accommodate them although, emerging integrated approaches that bridge financial consideration alone with strategic (contextual) issues such as balanced score card are addressing this view [10].

Ryan and Harrison [26] highlight the significant cost associated with change management; prepar- ing the organizational-fabric (culture) for the adoption of information systems. Investment decision-makers often fail to include adequate training costs associated with change management, in addition. For example, resistance to change affects the successful implementation of a new system. Similarly, there is a need to consider broader educational development and draw a distinction between training and education; the former is about developing skills where as the latter is more about developing an appreciation about why certain investment decisions are taken, and its impact to the organization.

Ryan and Harrison [26] state that the most social subsystem costs considered by decision-makers are financially tangible ones; those that can be included in internal accounting reports. For example, training costs were the most frequent social subsystem cost cited by $59 \%$ of executives surveyed. Change management was cited by $17 \%$ of executives as being a significant cost associated with planning, overseeing, and communicating information to the end user about IT induced change. Another social subsystem cost is the on-the-job learning curve, which is the time period when employees learn and become proficient about using information technology with a broader system.

From their interviews, Ryan and Harrison [26] were able to identify other subsystem costs brought forward by executives. An example of these costs is management issues, which identifies the costs associated with an increased role and responsibilities, conflict, loss of power or control, employee moral and job dissatisfaction. The results of the study also show that these missed subsystem costs were considered by executives but after the IT acquisition, or during system implementation. This therefore enforces the authors' stance of culminating existing cost taxonomies so that others can use them as a frame of reference during the investment decision-making process.

\section{Direct and indirect human and organizational cost taxonomy}

Irani et al. [11] propagated that the costs associated with the adoption of IT/IS can be classified as 
having direct and indirect [human and organizational] characteristics. Irani and Love [13], and then later Irani [10] empirically validated these original theoretical cost taxonomies that were incurred during the implementation of a manufacturing information system. The direct cost components are those which can be attributed to the implementation and operation of new technology, and as a result are those most considered by decision-makers during the use of traditional appraisal techniques. Indirect costs however, are those that cannot be readily identified, managed and controlled, with the consequence of not doing so having been explained by Kaplan [15].

\subsection{IT/IS direct costs}

Remenyi et al. [24] suggest that direct costs such as those identified in Table 10 are often the only costs taken into account by managers when deciding their IT/IS budgets. These costs are often underestimated and also increase frequently due to unexpected circumstances. For example, in the case of additional requirements for hardware accessories, a system manager may decide to plan for the future and increase the storage and memory capacity so as to host future applications or data. In other words, changes or additional system needs (hardware/software) affect the estimated direct cost of IT/IS. During which, the systems' objectives may not only change due to changes in the business environment but may also require changes/alterations to existing software or hardware needs. These factors may lead to an increase in the presence of indirect costs. After the system is implemented not only would additional requirements for hardware/software increase but new business needs may also emerge. Table 10 summarizes the direct costs associated with IT/IS projects as identified and classified by Irani and Love [13].

Despite being an indirect cost in pure accounting terms, overhead costs are considered direct costs. The reason for this is that they are associated with the operation of the system. For example, space, electricity, toner cartridges, disks and papers are directly related with the operation of the system.

\subsection{Indirect human costs}

The introduction of new information systems affects people within the organization and is translated into an indirect human costs. New systems

Table 10

Direct costs (adapted from Irani and Love [13])

\begin{tabular}{ll}
\hline Direct project costs & Direct IT/IS costs \\
\hline Environmental operating costs & Uninterruptible power supply \\
Hardware costs & File server \\
& Dumb terminals \\
& Backup tape streamer \\
Software costs & Network printer \\
& Key vendor software module \\
Installation and configuration & Relational database software \\
& Additional networking software \\
& Consultancy support (partially grant funded) \\
& Network wiring, junctions and connectors \\
Overhead & Installation hardware \\
Training costs & 'In-house' customising time \\
Maintenance costs & Re-engineering business processes to suit software \\
& Running costs: electricity, insurance premium rises \\
& Consumables: toner cartridges, disks and paper \\
& Database software course \\
& Yearly service contract (hardware)
\end{tabular}


Table 11

Indirect human costs (adapted from Irani [10])

\begin{tabular}{ll}
\hline Indirect human costs & Cost/factors drivers \\
\hline Management/staff resources & Integrating the new system into work practices \\
Management time & Devising, approving and amending IT strategies \\
Cost of ownership: system support & Vendor support/trouble shooting costs \\
Management effort and dedication & Exploring the potential of the system. Linking and integrating new systems together \\
Employee time & Detailing, approving new systems together \\
Employee training & Being trained to manipulate the system and training others \\
Employee motivation & Interests in using the system reduces as time passes \\
Personnel issues & Changes in salaries: pay increase base on improved employee flexibility \\
& Staff turnover: increases in interview costs, induction costs, training costs \\
& based in the need for skilled human resources \\
Software disposal & The removal of all software prior to disposal \\
\hline
\end{tabular}

introduce the concept of change in the way work is done. This change requires management to invest time, effort, and dedication to plan and amend their IT strategies, and to explore the potential of the new system. The human (management/staff) resources, their time, effort, and dedication are indirect human costs incurred by the new system, as without the system the organization would not need to fund such activities. When staff acquires new skills due to the introduction of IT/IS, they might ask for an increase in salary or be 'snatched' by competitors (i.e., staff turnover), which introduces a recruitment cost to the business (interviews, induction, training, etc.). Table 11 summarizes the indirect human costs associated with IT projects identified and classified and validated by Irani and Love [13].

Remenyi et al. [24] explain that management time is one of the largest indirect human costs in IT/IS projects. Management time is the time spent by managers to assess and explore the potential of the new systems and also the time spent on integrating new systems together (if there are more than one system being developed or running already). Another important indirect human cost is the one associated with the systems' support and troubleshooting. Systems support is the support provided by the IT staff to the different users of the system. IT staffs tries to solve problems through troubleshooting and when needed, the software vendor's technicians may also be asked to solve more complicated problems.

In addition to the last two indirect human costs, there are Human Resource Issues that encompass factors such as changes in salaries due to employees developing new skills thus, increasing their flexibility and overall contribution towards the organization. These employees may demand a raise in their salaries or else the organization might have to face the cost implications of a high staff turnover. Increases in staff turnover may be due to the un-satisfaction of the employees with their current positions or salaries, as they feel that they are overqualified for their current job and try to seek improved financial remuneration. Competitors are another threat to any organization that has highly qualified trained employees. Competitors try to s teal these trained employees and thus, not needing to invest in training/education but rather exploit the investment made by their previous employer.

\subsection{Indirect organizational costs}

The second category of indirect costs is the indirect organizational costs. Table 12 identifies a number of indirect organizational costs (identified and classified by Irani [10]). Most of the indirect organizational costs occur when the new system is implemented. Starting with a loss in productivity, employees attend training courses that then train others. They go through a period of adaptation to the new systems' functions. Possible employee resistance might occur; meaning that they will resist training and thus end up being ignorant about the new system, and not being productive. The result therefore will be a loss in productivity and opportunity cost. 
Table 12

Indirect organization costs (adapted from Irani [10])

\begin{tabular}{|c|c|}
\hline Indirect organizational costs & Cost drivers/factors \\
\hline Productivity loss & Developing and adapting to new systems, procedures and guidelines \\
\hline Strains on resources & $\begin{array}{l}\text { Maximizing the potential of the new technology through integrating } \\
\text { information flows and increasing information availability }\end{array}$ \\
\hline Business process re-engineering & The re-design of organizational functions, and processes \\
\hline Organizational re-structuring & Covert resistance to change \\
\hline Convert resistance & Unwilling to make the transition from the old system to the new system \\
\hline \multicolumn{2}{|l|}{ Opportunity, cost and risk } \\
\hline Hardware disposal & The removal of all hardware prior to environmental friendly disposal \\
\hline
\end{tabular}

Re-designing business processes and IS are usually related. The reason for this is that information systems are enablers or drivers of organizational change [27]. That is why Business Process Re-engineering (BPR) is seen as both a direct and indirect organizational costs. In the case of BPR being a direct cost, it could be that organizational processes need to change to suit the way the software functions. As for the BPR being an indirect cost, it could be because a new change imposed by the organization impacts the way the software should work. BPR cannot be avoided when a new system is implemented. The reason for this is that every new system introduces change in the way work is done, and if this is not the case, then the impact of the system is in question.

It is noticeable in Table 12 that loss in productivity is caused by different indirect human costs factors (employee time, training, motivation, management time, effort and dedication) thus, they can be considered as cost drivers contributing towards the loss in productivity. Additionally, organizational re-structuring costs go beyond covert resistance to change, and include the actual cost of re-structuring the organization.

\section{Cost division taxonomy: Management, employee, finance, and maintenance}

In an attempt to explore cost as a criteria of information system failure, Mohamed and Irani [19] explored the cost of adopting an information system and [its] impact on both employees and the organization. In doing so, resulting in a cost division taxonomy for classifying the indirect human cost factors associated with IT/IS investments. This taxonomy seeks to support decisionmakers in being better informed about the indirect human costs associated with IS-adoption.

The taxonomy proposed by Mohamed and Irani [19] allocates indirect human costs to organizational divisions. This results in the proposal of four cost categories, namely Management, Employee, Finance, and Maintenance (MEFM). Table 13 described in details each of the four categories.

Mohamed and Irani [19] then identified a set of potential indirect human cost factors and matched them with their respective cost categories as is shown in Table 14.

A detailed description of various indirect cost factors that sit within the MEFM division are discussed below:

- Time: Spent by either managers transferring their experience to the IS staff or by staff training to use the system or helping others to use the system. During this time, neither the managers nor the employees are doing their jobs and are thus, not directly productive. This in its turn leads to a loss in productivity.

- Learning costs: Refers to the temporary loss in productivity due to the learning curve experienced by both managers and employees during the introduction of a new system or technology. Managers and employees need time to adapt and be familiar with the new system.

- Resistance: Managers might resist a new system that brings a power shift. This could result in weakening political strengths of stakeholders. As for employees, they might resist a new system because they are familiar with the old 
Table 13

Taxonomies of indirect human costs associated with IS development

\begin{tabular}{ll}
\hline IS divisions & Description \\
\hline Management & People in this division are responsible for setting the strategy of the organization \\
& They are in charge of all of the organization's legalities \\
& The budget of this division is usually allocated to direct costs such as equipment, salaries, and training \\
& Indirect human costs would include re-defining roles, reduction in knowledge \\
This division is responsible for all issues concerning the employees in an organization \\
It would have a complete database record of each employee within the organization \\
The budget of this division is usually allocated to direct costs such as equipment, new systems, and paper work \\
Finance & Indirect human costs would include, deskilling, reduction in knowledge base, and redundancy \\
& This division is responsible for allocating budgets to all departments including their own department \\
Maintenance & The budget in this division usually includes direct costs such as payroll calculations \\
& Indirect human costs would include staff turnover, and training \\
& This division is responsible for all aspects of technology within an organization \\
& They setup and maintain the IT infrastructure and aid in future development when needed by the business \\
& Areas of costs include, employment of staff, hardware costs, staff training
\end{tabular}

Table 14

Mapping indirect human costs to IS divisions (from Mohamed and Irani [19])

\begin{tabular}{|c|c|c|c|c|}
\hline \multirow[t]{2}{*}{ Indirect human cost elements } & \multicolumn{4}{|l|}{ Cost category } \\
\hline & Management & Employee & Finance & Maintenance \\
\hline Time & $\checkmark$ & $\checkmark$ & & $\checkmark$ \\
\hline Learning & $\checkmark$ & $\checkmark$ & & $\checkmark$ \\
\hline Resistance & $\checkmark$ & & & $\checkmark$ \\
\hline Control system & $\checkmark$ & & & \\
\hline Effort and dedication & $\checkmark$ & & & \\
\hline Re-define roles & $\checkmark$ & $\checkmark$ & & \\
\hline Training & & $\checkmark$ & $\checkmark$ & $\checkmark$ \\
\hline Allocation of employee & & $\checkmark$ & & \\
\hline Integration & & $\checkmark$ & & $\checkmark$ \\
\hline Change in salary & & & $\checkmark$ & $\checkmark$ \\
\hline Staff turnover & & & $\checkmark$ & $\checkmark$ \\
\hline Loss in productivity & $\checkmark$ & $\checkmark$ & & $\checkmark$ \\
\hline Displacement & $\checkmark$ & $\checkmark$ & & \\
\hline Reduction in knowledge & $\checkmark$ & $\checkmark$ & & \\
\hline Deskilling & & $\checkmark$ & & \\
\hline Redundancy & $\checkmark$ & $\checkmark$ & & $\checkmark$ \\
\hline Morale hazard & $\checkmark$ & $\checkmark$ & & \\
\hline Disruption & $\checkmark$ & $\checkmark$ & & \\
\hline Belief, feeling, and perception & & $\checkmark$ & & \\
\hline
\end{tabular}

system, or due to the complexity of the new system avoid using it. This resistance could be covert, making it difficult for managers to identify and ultimately leads to a loss in job productivity.

- Effort and dedication: This cost occurs during the introduction of a new system, as both managers and employee spend time, exploring, discovering the full potential of the new system.
Managers and employees are less productive during this transition period between the old and the new system.

- Re-defining roles: The introduction of a new system brings change to the organization, and leads to organizational re-structuring. The organization's hierarchy can be re-defined; levels can be reduced to achieve a greater position of flexibility. This change in roles can result in 
the need for re-training as well as translate into redundancies; both of which have significant costs attached.

- Displacement: Also called re-allocation costs, whereby people and operations have to be reallocated to accommodate a new system.

- Disruption: The time when IT staff are not doing their work and responding to users enquires about the new system, until they become adjusted to it and feel confident in operating it.

- Reduction in knowledge base: This is usually due to a high rate of staff turnover; either because of a reduction in manpower introduced by the new system or by highly qualified and experience staff being recruited by the competition. This might result in a reduction in employee knowledge base, as it might take sometime before newly employed staff becomes experienced with the system and the organization as a whole.

- Moral hazard: The state where the IS manager is only interested in gaining knowledge that will help him employed and in a position of power thus, ensuring an optimum market value [for personal skills] rather than being interested in benefiting the organization.

- Deskilling: The inability to fully utilize the potential skills of an employee. This situation might appear when a new system does not require a highly skilled staff member to operate it. In this case, either the highly skilled staff member might consider turning to competitors that need their skills, or the organization continues to employ him and pay an inflated salary.

As shown in Table 12, employee and management divisions have a high number of indirect human costs. It also appears that time, learning, training, loss in productivity, and redundancy costs seems to be shared by all IS divisions.

\section{Acquisition/administration: Control and operation cost taxonomy}

To achieve control over IT expenditure and help reduce information technology costs, David et al. [4] use a total cost of ownership (TCO) ap- proach to identify the costs associated with owning and maintaining a personal computer or workstation within an organization. As organizational spending on IT adoption is both a necessity and fairly large proportion of turnover, TCO is used as a measure to assess the effectiveness of an organization's IT expenditure. TCO is divided into two sets of cost factors; acquisition costs and administration costs.

The acquisition cost is the initial costs of a system, which is the cost of hardware and software. As it is difficult for any organization to gain a competitive edge by reducing the cost of its hardware and software [4] alone, they tend to have greater control over the administration costs therefore seeking competitiveness through differentiation. Administration costs are then divided into control and operations costs, where the earlier cost is optional and is incurred in the form of centralization and standardization when an organization wants to reduce the operations costs and/or improve their service levels. David et al. [4] define operations costs as 'the costs associated with the ongoing operation of an IT system, and they must be incurred pp. 103. Table 15 lists the cost elements associated with each of the costs categories.

The cost taxonomies presented in Table 15 are now described in more detail below:

Table 15

Acquisition/administration cost categories

\begin{tabular}{ll}
\hline Category & Factors \\
\hline Acquisition cost & Hardware \\
Sdministration costs & \\
Control & Implementation and maintenance \\
of centralization & Implementation an maintenance \\
of standardization \\
Support \\
Evaluation \\
Installation/upgrades \\
Training \\
Downtime \\
Futz \\
Auditing \\
Viruses \\
Power \\
Consumption \\
\hline
\end{tabular}




\section{Acquisition costs}

- Hardware: Monitors, peripherals, CPU's, servers, etc.

- Software: Packages, operating systems, database management systems, etc.

\section{Administration control costs}

- Centralization: Specialized hardware (such as intelligent self-monitoring complements that notify a network management console when a problem occurs) and software (such as directory services and desktop management interfaces) are needed to implement and maintain a centralized system. Support staff has to be trained to use theses systems and monitor/ troubleshoot.

- Standardization: Hardware and software may have to be replaced by hardware and software conforming to selected standards. Users may have to be trained in the use of the new standardized software, and non-standardized hardware may be more expensive than standard hardware.

\section{Administration operations costs}

- Support: In-house staff or support contract is required to address hardware and software problems as they arise - this may be an outsourced service.

- Evaluation: New/upgraded versions of applications, operating systems, and hardware are constantly being released. Before new hardware or software is installed, it must be evaluated to determine: whether it does what it is supposed to do, as well as determining compatibility with existing IT environments.

- Installation/upgrade: After a new technology is evaluated, it must be installed or upgraded. Hardware and software upgrades are often related; new software generally requires more powerful hardware, forcing hardware upgrades.

- Training: Training allows users to get the most from their workstations and software environment. Training can take two forms: Formal training in a classroom setting and self-training as end-users learn how to work new applications. Software and hardware installations/ upgrades generally require some retraining of the end-users.

- Downtime: Downtime arises not only when software or hardware failure occur but also when software or hardware installations/ upgrades occur. When a system fails, the organization incurs costs for the non-working system, non-working employees, and necessary repairs to make the system function again.

- Futz: This cost lies not in the system itself but in the time employees spend using the system for non-working-related activities, such as searching the internet, checking personal emails, etc.

- Auditing: This is the cost of keeping track of technology assets, for example insurance purposes. Computers move around a lot, especially in large corporations. To determine which department has which asset is essential here, therefore some type of record keeping is required.

- Virus: Security threats increase a computers' TCO in two ways: they can destroy important data expensive to recreate, and they can cause a computer to crash completely, resulting in downtime.

- Power consumption: Electrical power consumption per workstation. In addition, computers generated generate heat, which can increase air-conditioning costs.

- Disposal: The environmental removal and disposal of hardware is an increasing cost that organizations are now realising.

Although not guarantied to work in reality, centralization and standardization are two methods proposed by David et al. [4] to reduce TCO. Centralization aims to unify software access, distribution, and network administration in a few central locations. As for standardization, the aim is to minimize the hardware and software configuration differences among individual workstations. Both methods aim to reduce the TCO by simplifying operations. Their lies a problem when trying to 
reduce the TCO, which was described by David et al. [4] to be the relation between IT costs and IT service level. This relation is thought to be directly proportional, which makes the reduction in TCO negatively affect IT service level. They claim that previous research [8] showed that the reduction in IT operations costs is often associated with a reduction in IT service levels. Therefore, careful planning is required to avoid this consequence.

\section{Synthesis of cost taxonomies}

The presented cost taxonomies offer a variety of cost classification perspectives, while there is a resemblance between cost classifications (even thought they are listed under different taxonomies), there are cost factors that differentiate each cost taxonomy from one another. Table 16 summarizes the different cost factors listed in the various taxonomies and, indicates the authors that mentioned each of the cost elements thus, making it possible to identify the similarities and differences that exist.

From Table 14, it can be seen that none of the cost factors listed have been included in a single cost taxonomy. The process of IS evaluation is one through which managers identify and appraise the perceived benefits, costs and risks of an investment. There are many models that exist in the normative literature, which seek to assist managers in identifying the costs associated with their investments in technology however experience is often the overwhelming influence. What makes the evaluation of information system investments difficult is the set of social and organization aspects that interplay and the increased recognition of their importance in technology management. These costs are difficult to identify, quantify, manage and then control. Yet, such costs cannot be avoided nor ignored, and cannot be accommodated within existing traditional economic appraisal techniques although, increasingly emerging approaches such as the balanced score card are sympathetic to their consideration. The reason for this is that traditional appraisal techniques are based on conventional accountancy techniques, which cannot accommodate costs that are not financially quantifiable, and as Table 15 has shown, there are an increasing number of costs that are nonquantifiable.

\section{Conclusions}

Organizations are increasingly seeking a competitive edge through cost-managing their technology. However, this management should not be restricted to reducing the cost of IT alone but rather through identifying where IS-related costs lie. This paper has sought to provide an insight for decision-makers into the complexity of identifying the costs associated with information system investments. It has demonstrated that although traditional approaches to investment appraisal are inadequate in accommodating the portfolio of investment related costs, emerging integrated approaches are making considerable progress to support tier inclusion. The authors of this paper have identified eight IS-cost taxonomies, which seek to contribute towards developing a deeper understanding of IS-related costs through their identification and classification. Emerging approached to evaluation such as the balanced scorecard and information economics attempt to integrate many of the limitations inherent in traditional approaches. In light of this, integrated approaches have the potential of accommodate indirect/hidden costs associated with information systems adoption. Therefore, to carry out a robust comprehensive evaluation process, it is necessary for decisionmakers to not only integrate hidden/indirect costs into the decision-making process but also categorize such costs and ensure that this forms part of the organizational learning for future information systems adoption. The rational here being 'if such costs can be identified; they can then be managed. Such management supports reduction and control, which lie at the genesis of the rational that underpins the efficiency and effectiveness of cost managing information systems. 
Table 16

Comparison of cost taxonomies

\begin{tabular}{|c|c|c|c|c|c|c|c|c|}
\hline \multirow[t]{2}{*}{ Categories } & \multicolumn{8}{|l|}{ References } \\
\hline & $\begin{array}{l}\text { Dier and } \\
\text { Mooney [5] }\end{array}$ & $\begin{array}{l}\text { Kusters } \\
\text { et al. [16] }\end{array}$ & $\begin{array}{l}\text { Remenyi } \\
\text { et al. [23] }\end{array}$ & $\begin{array}{l}\text { Anandarajan } \\
\text { and Wen [1] }\end{array}$ & $\begin{array}{l}\text { Ryan and } \\
\text { Harrison [26] }\end{array}$ & $\begin{array}{l}\text { Irani } \\
\text { et al. [13] }\end{array}$ & $\begin{array}{l}\text { Mohamed } \\
\text { and Irani [19] }\end{array}$ & $\begin{array}{l}\text { David } \\
\text { et al. [4] }\end{array}$ \\
\hline Development & & - & & - & - & & & \\
\hline Training & - & - & & - & - & - & - & - \\
\hline Implementation & & - & & & & & & \\
\hline Operations & & - & & & & & & - \\
\hline Maintenance & - & - & - & - & & - & & \\
\hline Security & & - & & & & & & \\
\hline Phasing out & & - & & - & & & & \\
\hline Communication & - & & & - & - & - & & \\
\hline Hardware & - & - & - & - & - & - & & - \\
\hline Package software & - & & - & - & - & - & & - \\
\hline Custom software & - & & & - & & & & \\
\hline System software & - & & & & & & & - \\
\hline Cabling/building & - & & & & & & & \\
\hline Project management & - & & & & & & & \\
\hline Licenses & - & & & & & & & \\
\hline Support & - & & & - & & & & - \\
\hline Modification & - & & & & - & & & \\
\hline Upgrades & - & & & & - & & & - \\
\hline Overheads & - & & & & & - & & \\
\hline Installation and configuration & & - & & & & - & & - \\
\hline Management/staff resources & & & & & & - & - & \\
\hline Management time & & & & & & - & - & \\
\hline Cost of ownership: system support & & & & - & & - & & \\
\hline Management effort and dedication & & & & & & - & - & \\
\hline Employee motivation & & & & & & - & & \\
\hline Employee time & & & & - & - & - & - & \\
\hline Personnel issues & & & & & & - & & \\
\hline Software disposal & & & & & & - & & \\
\hline Productivity loss & & & & & & - & - & \\
\hline Strains on resources & & & & & & - & & \\
\hline Business Process Re-engineering (BPR) & & - & & & & - & - & \\
\hline Organizational re-structuring & & - & & & & - & & \\
\hline Implementation risks (covert resistance) & & - & & - & - & - & - & \\
\hline Opportunity costs and risks & & & & & & - & & \\
\hline Hardware disposal & & & & & & - & & \\
\hline Data communication & & & - & & & & & \\
\hline Commissioning & & & - & & & & & \\
\hline Infrastructure & & & - & & - & & & \\
\hline Staff related costs (changes in salaries) & - & - & - & & & & - & - \\
\hline
\end{tabular}




\section{Acknowledgement}

The authors would like to acknowledge the financial support provided by Engineering and Physical Sciences Research Council (GR/M95066 and GR/R08025) and the Australian Research Council.

\section{References}

[1] A. Anandarajan, H.J. Wen, Evaluation of information technology investment, Management Decision 37 (4) (1999) 329-337.

[2] J. Ballantine, S. Stray, Financial appraisal and the IS/IT investment decision making process, The Journal of Information Technology 13 (1) (1998) 3-14.

[3] J.A. Ballantine, S. Stray, Information systems and other capital investments: Evaluation practice compared, Logistics Information Management 12 (1-2) (1999) 78-93.

[4] J.S. David, D. Schuff, R. St. Louis, Managing your IT total cost of ownership, Communications of the ACM 45 (1) (2002) 101-106.

[5] D.H. Dier, J.G. Mooney, Enhancing the evaluation of information technology investment through comprehensive cost analysis, in: Proceedings of the 1st European Conference for IT Evaluation, Henley Management College, Henley on Thames, 1994.

[6] M.J. Earl, Management Strategies for Information Technology, Prentice-Hall, New York, NY, 1989.

[7] J. Heo, I. Han, Performance measure of information systems (IS) in evolving computing environments: An empirical investigation, Information and Management 40 (4) (2003) 243-256.

[8] R. Hirschheim, M. Lacity, Four stories of information technology insourcing, in: R. Hirschheim, A. Heinzl, J. Dibbern (Eds.), Information Systems Outsourcing in the New Economy, Springer-Verlag, Berlin, 2002, pp. 348-391.

[9] B. Hochstrasser, Evaluating IT investments - matching techniques to projects, Journal of Intelligent Systems 5 (1990) 215-221.

[10] Z. Irani, Information systems evaluation: Navigating through the problem domain, Information and Management 40 (2002) 11-24.

[11] Z. Irani, J.-N. Ezingeard, R.J. Grieve, Integrating the costs of a manufacturing IT/IS infrastructure into the investment decision-making process, Technovation 17 (11/12) (1997) 695-706.

[12] Z. Irani, P.E.D. Love, Developing a frame of reference for ex-ante IT/IS investment evaluation, European Journal of Information Systems 11 (2002) 74-82.

[13] Z. Irani, P.E.D. Love, The propagation of technology management taxonomies for evaluating investments in information systems, Journal of Management Information Systems 17 (3) (2001) 161-177. 
[14] Z. Irani, M. Themistocleous, P.E.D. Love, The impact of enterprise application integration on information system lifecycles, Information and Management 42 (2) (2003) 177188.

[15] R.S. Kaplan, Yesterday's accounting undermines production, Harvard Business Review 62 (4) (1984) 95-101.

[16] R.J. Kusters, T.J.W. Renkema, Managing IT investment decisions in their organizational context: The design of 'local for local' evaluation models, in: Proceedings of the 3rd European Conference for IT Evaluation, Bath University School of Management, Bath University, Bath, 1996.

[17] P. Legris, J. Ingham, P. Collerette, Why do people use information technology? A critical review of the technology acceptance model, Information and Management 40 (3) (2003) 191-204.

[18] K. Milis, R. Mercken, The use of the balanced scorecard for the evaluation of Information and Communication Technology projects, International Journal of Project Management 22 (2004) 87-97.

[19] S. Mohamed, Z. Irani, Developing taxonomy of information system's indirect human costs, in: 2nd International Conference on Systems Thinking in Management, University of Salford, UK, 2002.

[20] D. Paula, L. Laurence, Control of the information systems function: The role of cost allocation, in: Proceedings of the 4th European Conference for IT Evaluation, University of Delft, The Netherlands, 1997.

[21] P. Powell, Information technology evaluation: Is it different? Journal of the Operational Research Society 43 (1) (1992) 29-42.
[22] P.L. Primose, Investment in Manufacturing Technology, Chapman and Hall, London, 1991.

[23] D. Remenyi, S. Michael, W. Terry, Outcomes and benefits for information systems investment, in: Proceedings of the 3rd European Conference for IT Evaluation, Bath University School of Management, Bath University, Bath, 1996.

[24] D. Remenyi, A. Money, M. Sherwood-Smith, Z. Irani, The effective measurement and management of IT costs and benefits, Computer Weekly, second ed. Professional Information Systems Book Series, Butterworth-Heinemann, Oxford, 2000.

[25] J.W. Renkema, E.W. Berghout, Methodologies for information systems investment evaluation at the proposal stage: A comparative review, Information and Software Technology 39 (1997) 1-13.

[26] S.D. Ryan, D.A. Harrison, Considering social subsystem costs and benefits in information technology investment decisions: A view from the field on anticipated payoffs, Journal of Management Information Systems 16 (4) (2000) $11-40$.

[27] J.A.A. Sillince, G. Harindranath, Integration of requirements determination and business process re-engineering: A case study of an Ambulatory Care and Diagnostic (ACAD) Center, European Journal of Information Systems 7 (1998) 115-122.

[28] M. Wheatley, Hidden costs of the humble PC, Management Today (January) (1997) 52-54. 